\title{
The Analysis of Health Care Coverage through Transition Matrices Using a One Factor Model
}

\author{
Eric D. Olson ${ }^{1}$, Billie S. Anderson ${ }^{2}$ and J. Michael Hardin ${ }^{1}$ \\ ${ }^{1}$ University of Alabama at Tuscaloosa and ${ }^{2} S A S$ Institute
}

\begin{abstract}
This paper studies the affect the tax environment has on health care coverage of individuals. This study adds to the current literature of health care policy by examining how individuals switch types of health care coverage given a change in the tax environment. The distribution of health care coverage will be investigated using transition matrices. Then, a model is used to determine how the individuals might be expected to switch insurance types given a change in the tax environment. Based on the results of this study, the authors give some recommendations on what the implications of the results may mean to health care policy makers.
\end{abstract}

Key words: One-factor model, tax policy, transition matrices.

\section{Introduction}

There is an extensive body of literature regarding the welfare losses associated with health insurance tax subsidies. Many health economists have noted that the U.S. tax preference for employment-related health insurance is both regressive and distortionary. However, previous research has indicated that the tax subsidy helps curb adverse selection through risk pooling. Positive welfare effects of risk pooling are derived from the assumption that health care is a public good. Positive externalities from health care primarily come from individuals seeking preventive care to reduce the spread of contagious disease and illness to others in society. Thus, access to preventive care through health insurance implies that risk pooling can improve social welfare and that some level of subsidization for consumption could be efficient (Ketsche 2004). However, policy makers in support of the elimination of the tax subsidy believe welfare losses due to inefficiencies with the tax subsidy are larger than the welfare benefits accrued through risk pooling. Any reduction in the tax subsidy could affect employment-based pooling and thus the distribution of coverage.

This analysis is novel in that we estimate the type of insurance an individual is likely to have conditional on the tax environment through transition matrices. 
This paper presents a one-parameter relationship between the tax environment and health insurance transition matrices. We seek to add to the current literature by examining how the probabilities of individuals switching types of health care coverage change given a change in the current tax environment and if the change is uniform across income levels. The purpose of this paper is twofold. First, we investigate the distribution of coverage through transition matrices of those whose health insurance was provided by their employer, insurance purchased directly from an insurer, those enrolled in Medicare or Medicaid, and those who are not covered under any health plan. Second, we model how one might expect the transition probabilities to change for individuals at different income levels given a change in the tax environment. The paper proceeds as follows. Section two gives a brief literature review. The mathematics of the model is presented in section three. Section four reports the empirical results and section five concludes with a discussion related to what the results might mean to policy makers.

\section{Literature Review}

The current tax system subsidizes medical care in two ways. First, employer insurance premium payments are excluded from income and payroll taxes. Second, individuals can deduct individual expenditures on medical care and insurance if it rises above a certain level. Presently, tax law dictates that health insurance premiums are tax exempt if purchased by the employer. However, health insurance premiums for individuals who purchase private insurance directly are generally not exempt. Thus, workers prefer more of their total income to be paid through health insurance coverage. As a result, many believe that employers provide too much health care coverage which has resulted in increased levels of health spending. In addition to the incentive to over-purchase health insurance the current tax policy regarding health insurance is also highly regressive. Bloche (2006) estimated that the average tax benefit for health expenditures was approximately $\$ 1,482$ per family in 2004 . However, the average was $\$ 2,780$ for families that earned $\$ 100,000$ or more and only $\$ 102$ for families that earned less than $\$ 10,000$ per year. He reports that 26.7 percent of the tax benefit expenditures are credited to families that earn $\$ 100,000$ or more while comprising only 14 percent of the total population while 28.4 percent of the tax expenditures went to families with incomes below $\$ 50,000$ which comprise 57.5 percent of the population. Bloche (2006) concludes that families with higher incomes will be in higher tax brackets and are more likely to have health coverage through their employer.

Selden and Gray (2006) estimated that the size of the federal and state tax subsidies for health insurance in 2006 was $\$ 208.6$ billion. Selden and Bernard (2004) argue that healthy workers prefer employment-related risk pooling because of its potential to reduce uncertainty for the future. However, the authors 
do note the regressive nature of the subsidy and conclude that the tax subsidy will generally be larger for high income families than for poorer families, larger for older workers than younger workers, larger for workers in multi-person families than workers living alone, larger for non-Hispanic whites than for blacks or Hispanics, and larger for workers with above average health risks than those with below-average health risks. Families that opt out of employment insurance could value the option to hedge their risk in the future. Thus, they conclude that if the goal is to decrease those who uninsured or covered by public insurance the current tax subsidy is not an effective tool.

Feldmam, Dowd, and Maciejewski (2001) provide empirical evidence that employers are more likely to provide a subsidy to plans preferred by high-risk workers when the benefits of long-run risk protection are greater. Selden (1999) showed in a theoretical model that linear subsidies for health insurance premiums could balance over-consumption and adverse selection. Ketsche (2004) presents a theoretical model with empirical evidence and finds that the effect of the tax subsidy on quantity is stronger for the low-risk individuals and that low-risk individuals will generally participate in more generous coverage. He argues that the subsidy is effective in controlling adverse selection but worsens moral hazard. The author concludes pooling could be welfare enhancing if the loss in welfare from crosssubsidization in health plans is smaller than the inefficiencies generated through: public expenditures made to provide care for the uninsured and underinsured, cost-shifting at the point of delivery to compensate for the uninsured and underinsured who obtain care, but do not pay the full cost for that care, and under provision of care to the uninsured and underinsured.

Florence and Thorpe (2003) examine the trade-off between total premium spending and risk segmentation associated with the use of premium subsidies. Their empirical study focuses on the Federal Employees Health Benefits Program (FEHBP). They find that the U.S. government could greatly decrease the premium on the (FEHBP) subsidy without inducing severe risk segmentation. However, their results do not model the change in overall plan premiums that would occur as the plan risk pool or the competitiveness of the market changes reduction or elimination of the tax subsidy will enhance welfare if it causes individuals to reduce consumption of health care with low marginal benefits. As noted above, reducing the tax subsidy will more than likely cause segmentation of high-risk and low-risk individuals meaning that those with greater risk could lose access to employer's plans and lose health insurance altogether. 


\section{Methodology}

\subsection{Transition Matrices}

The probability of an individual migrating from their current insurance category to any other category, within a pre-defined time horizon, can be expressed in terms of a transition matrix. A transition matrix is a square table of probabilities based on historical data that indicates the probability of an individual moving from one insurance category to another. The four insurance categories under study are PrivateE, PrivateD, public and none. PrivateE insurance was defined as those whose health insurance was provided by their employer. PrivateD was defined as those who purchased health insurance directly. Public insurance was defined as those who obtained health insurance from Medicare or Medicaid. None was defined as those who were not currently covered by a health care plan. As noted above, Bloche (2006) reported that 26.7 percent of the federal tax expenditures were credited to families that earned $\$ 50,000$ or more and 28.4 percent of tax expenditures went to families with incomes below $\$ 50,000$. Using Bloche (2006) as a guide we split individuals into two different income levels: less than $\$ 50,000$ and greater than $\$ 50,000$. The data at the Panel Study of Income Dynamics (PSID) was used to create the transition matrices for each of the income groups. The PSID includes variables regarding individuals' income, health care expenditures, health insurance type, and demographic behavior. The specific variable used to identify insurance type began being collected in1999. Thus, data used in this analysis spans from 1999-2005. Data was collected for two year periods. The probability transition matrices represent the movement of individuals among the insurance categories over a two year period. Table 1 gives an example probability transition matrix for the time period 1999 to 2001 for those individuals who made less than $\$ 50,000$.

Table 1: Transition matrix for 1999-2001 for individuals who made less than $\$ 50,000$

\begin{tabular}{cccccc}
\hline & 2001 & PrivateE & PrivateD & Public & None \\
\hline \multirow{1}{*}{1999} & PrivateE & 0.898214 & 0.022857 & 0.011786 & 0.067143 \\
& PrivateD & 0.423469 & 0.44898 & 0.010204 & 0.117347 \\
& Public & 0.193878 & 0.056122 & 0.55102 & 0.19898 \\
& None & 0.46021 & 0.035285 & 0.108859 & 0.395646 \\
\hline
\end{tabular}

The rows represent the previous time period, $t-1$, and the columns represent the present time period, $t$. The elements on the main diagonal report the proportion of individuals that did not change insurance types. For example, the entry in the top left of the table indicates that 89.82 percent of the individuals who had PrivateE insurance in 1999 still had that insurance in 2001. Off-diagonal 
elements indicate a migration from one insurance coverage type to another. For example, the second probability in the first row indicates that 2.29 percent of individuals moved from PrivateE in 1999 to PrivateD in 2001.

Once the transition matrices are developed for the time periods specified, an average transition matrix can be computed. The average transition matrix is formed by summing the probabilities from the probability matrix for each entry in the matrix and dividing by the total number of individuals for that entry.

\subsection{One Factor Model}

The health insurance status of each individual can be decomposed into two parts: a systematic component that is shared by all individuals and an idiosyncratic component specific to each individual (Forest, Belkin, and Suchower 1998). The idiosyncratic component may be represented by a transition matrix. The decomposition is represented as follows. If $X_{t}$ denotes a continuous insurance status-change indicator for a particular individual at time $t$, the one factor model will decompose $X_{t}$ into a systematic component $Z_{t}$ and a component unique to each individual $\epsilon_{t}$ and can be written as

$$
X_{t}=\rho Z_{t}+\sqrt{1-\rho^{2}} \epsilon_{t}
$$

where $Z_{t}$ measures the "tax environment" at time $t$. Note that an assumption of the model is that and $Z_{t}$ are standard normal random variables and mutually independent (Forest, Belkin, and Suchower 1998). The constant $\rho$ measures the correlation between the systematic component and the insurance status-change indicator $X_{t}$. In other words, $\rho$ represents to what extent the variation in the insurance-change indicator $X_{t}$ is explained by the systematic component $Z_{t}$.

As noted above, the systematic component $Z_{t}$ must be standard normal and common to all individuals. In this study, the primary goal was to model how individuals' health insurance might change if employers' contributions to health care plans are taxed. Thus, the systematic component chosen was " 1 minus U.S. average tax burden," which we refer to as the tax environment. The tax burden is calculated by dividing the official government tally of all taxes collected in each year by the official government tally of all income earned in each year. This percentage is what is properly called the nation's total tax burden (Tax Foundation $)^{1}$. The U.S. average is simply the average state/local tax burden plus the average federal tax burden for a given year. Thus, "1 minus U.S. average tax burden" is the percentage of income that is left over after the tax burden has been accounted for. The average tax burden for each of the past historical years was calculated and standardized. The tax environment values for each historical year and their standardized values are displayed in Table 2 .

\footnotetext{
${ }^{1}$ Tax Foundation, 2007. Tax data. Retrieved April 6, 2007. from www.taxfoundation.org
} 
Table 2: Tax environment figures for 1999-2005

\begin{tabular}{ccc}
\hline Time Period & Tax Environment & Standardized Tax Environment \\
\hline $1999-2001$ & 0.665 & -1.956 \\
$2001-2003$ & 0.690 & 0.617 \\
$2003-2005$ & 0.697 & 1.33 \\
\hline
\end{tabular}

Once the systematic factor has been accounted for, the movement among the individuals in the transition matrices is independent. More formally, the individuals are conditionally independent given $Z_{t}$ (Finger 1999).

An essential concept in the model is the distinction between unconditional and conditional event probabilities. Individuals' unconditional transition probability is the probability of migrating before a set time period given all information currently observable. The average probability transition matrix represents the unconditional transition probability. The conditional probability is the probability of migrating from one insurance category to another if we knew what the realized value of the systematic risk factors at the time horizon would be (i.e. the future systematic component) (Gordy 2002).

One can project the conditional transition matrices using a systematic component $Z_{t}$. This task is accomplished by computing a best fitted $\rho$ value. Consider the following objective function:

$$
\min \sum_{G} \sum_{g} \frac{n_{t, G}\left[P_{t}(G, g)-\Delta\left(x_{g+1}^{G}, x_{g}^{G}, Z_{t}\right)\right]^{2}}{\Delta\left(x_{g+1}^{G}, x+g^{G}, Z_{t}\right)\left[1-\Delta\left(x_{g+1}^{G}, x+g^{G}, Z_{t}\right)\right]}
$$

where $P_{t}(G, g)=\Phi\left(x_{g+1}^{G}\right)-\Phi\left(x_{g}^{G}\right)$,

$\Delta\left(x_{g+1}^{G}, x+g^{G}, Z_{t}\right)=\Phi\left((1-\rho)^{-1 / 2}\left(x_{g+1}^{G}-\sqrt{\rho} Z_{t}\right)\right)-\Phi\left((1-\rho)^{-1 / 2}\left(x_{g}^{G}-\sqrt{\rho} Z_{t}\right)\right)$

and $n_{t, G}$ is the number of transitions observed in time $t-1$ to $t$ from the rating $G$ at time $t-1$. The indices $G$ and $g$ represent sequences of integers rather than letters or other symbols. For this particular study $g_{1} \neq g_{2} \ni\{1,2,3,4\}$ and $G_{1} \neq G_{2} \ni\{1,2,3,4\} . P_{t}(G, g)$ denotes the probability that an individual migrates from a realized (i.e., observed) probability transition matrix category $G$ at time $t-1$ to a category $g$ at time $t$ and $\Phi(\cdot)$ represents the standard normal cumulative distribution function. In other words, $P_{t}(G, g)$ is the actual or the observed movement of the individuals in the probability transition matrices for each time period $\left.t . \Delta\left(x_{g+1}^{G}, x_{g}^{G}, Z_{t}\right)\right)$ denotes the $G$ to $g$ transitions for a given time period, $t$, as specified by the model. The $\Delta$ term is the model value for the $G$ to $g$ transition rate in year t (Forest, Belkin, and Suchower 1998). Thus, the objective function given in (3.2) takes the least-squares form in which the goal is 
to minimize the discrepancies between the observed transition probabilities and the model transition probabilities. For a chosen $\rho$ the objective function in (3.2) is minimized at each time period , $\left\{X_{t}\right\}$. Finding a $\rho$ using this methodology becomes difficult due to the lack of historical time periods. Thus, for each historical time period, we use a systematic component $Z_{t}$ (as described previously) and minimize the objective function in equation (3.2) with respect to $\rho$ to find a $\rho_{t}$ for that time period. Then we average $\rho_{t}$ at each time period to find the best fitted $\rho$.

Once an estimate of the correlation between the systematic component and the idiosyncratic components is computed, the average transition matrices and a given systematic component can be used to determine conditional transition matrices. The conditional transition matrices will give some insight into how the transition probabilities will change under different tax burden scenarios. The computation of the conditional transition matrices involves a derivative of the risk decomposition formula. As discussed in (Finger 1999), given a realization $Z_{t}$ for the U.S. tax burden, we can compute the conditional probability for each individual as $\left.\Phi\left(\left(1-\rho^{2}\right)^{-1 / 2}\left(\alpha_{i}-\rho Z\right) t\right)\right)$ where $\alpha_{i}=\Phi^{-1}\left(p_{i}\right)$, and $p_{i}$ is the probability that an individual moves from category to category for individual $i$.

\section{Results}

The analysis component of this study consisted of using the historical transition matrices for the past three time periods available and given a tax environment as the systematic factor, compute a best fitted $\rho$ value and adjust (i.e. compute conditional probability transition matrices) for different tax burden scenarios. The first scenario will examine the conditional probability transition matrix if the tax burden increases relative to the past six years. In this case, we will assume that the tax burden for 2005-2007 is 0.40 (corresponding $Z_{t}$ value is -1.92). The next scenario will examine the conditional probability transition matrix if the tax burden decreases relative to the past six years. The tax burden in this scenario will be 0.20 (corresponding $Z_{t}$ value is 1.96). For each high and low tax scenario, the revised $Z_{t}$ value was used to estimate an updated $\rho$ value to reflect the scenario. This type of analysis will be examined for each income level. The conditional probability transition matrices for different tax environments will be compared against the average transition matrix.

Table3 presents the average transition matrix and the conditional probability transition matrices for the two different tax environment scenarios for those individuals who make below $\$ 50,000$. 
Table 3: Average Transition and Conditional Probability Matrices for two different tax environment scenarios for those individuals who make less than $\$ 50,000$

\begin{tabular}{|c|c|c|c|c|c|}
\hline & & Private E & Private D & Public & None \\
\hline & Private E & 0.861 & 0.024 & 0.014 & 0.100 \\
\hline & Private D & 0.363 & 0.475 & 0.022 & 0.139 \\
\hline & Public & 0.177 & 0.040 & 0.581 & 0.201 \\
\hline & None & 0.442 & 0.029 & 0.129 & 0.386 \\
\hline \multicolumn{6}{|c|}{ Average Transition Matrix for 1999-2005 for individuals who made less than $\$ 50,000$} \\
\hline & 2007 & Private E & Private D & Public & None \\
\hline \multirow[t]{4}{*}{2005} & Private E & 0.869 & 0.026 & 0.016 & 0.089 \\
\hline & Private D & 0.378 & 0.489 & 0.024 & 0.108 \\
\hline & Public & 0.186 & 0.044 & 0.596 & 0.174 \\
\hline & None & 0.456 & 0.031 & 0.136 & 0.376 \\
\hline \multicolumn{6}{|c|}{$\begin{array}{l}\text { Conditional Probability Transition Matrix for } 2005-2007 \text { assuming high } \\
\text { tax environment for individuals who made less than } \$ 50,000\end{array}$} \\
\hline & 2007 & Private E & Private D & Public & None \\
\hline \multirow[t]{4}{*}{2005} & Private E & 0.849 & 0.021 & 0.0124 & 0.118 \\
\hline & Private D & 0.344 & 0.454 & 0.019 & 0.182 \\
\hline & Public & 0.163 & 0.036 & 0.561 & 0.240 \\
\hline & None & 0.421 & 0.026 & 0.118 & 0.436 \\
\hline
\end{tabular}

Conditional Probability Transition Matrix for 2005-2007 assuming low tax environment for individuals who made less than $\$ 50,000$

The regressive nature of the U.S. tax preference for employer based insurance is evidenced by noting that the probability of maintaining insurance through one's employers is lowest for those making below $\$ 50,000$ regardless of the tax environment and in comparison to the other three income groups. Comparing the None column in the average transition matrix with None column in the conditional probability matrix for the high tax environment, the probability of transitioning into no insurance decreases while the probability of transitioning into public insurance increases regardless of what type of insurance an individual had in the previous time period. The probability that individuals maintain either type of private insurance does not seem to change for individuals making less than $\$ 50,000$ in a high tax environment. This result seems to stem from individuals belief that in high tax environments public insurance programs will receive increased funding resulting in broader coverage. Comparing the transition matrix for the low tax environment to the average transition matrix, the opposite effect occurs. The probability of transitioning into no insurance in a low tax environment increases while the probability of transitioning into public insurance decreases regardless of what type of insurance an individual had in 
the previous time period. The reduction in the tax burden does not appear to be associated with enough additional wealth for lower-income individuals to buy private health insurance, which again demonstrates the regressive nature of U.S. health tax policy.

Table 4 display the average transition matrix and the conditional probability transition matrices for the two different tax environments for those individuals who made more than $\$ 50,000$.

Table 4: Average Transition and Conditional Probability Matrices for two different tax environment scenarios for those individuals who make more than $\$ 50,000$

\begin{tabular}{|c|c|c|c|c|c|}
\hline & & Private E & Private D & Public & None \\
\hline & Private E & 0.893 & 0.024 & 0.005 & 0.077 \\
\hline & Private D & 0.160 & 0.694 & 0.016 & 0.111 \\
\hline & Public & 0.111 & 0.000 & 0.750 & 0.139 \\
\hline & None & 0.585 & 0.024 & 0.080 & 0.310 \\
\hline \multicolumn{6}{|c|}{ Average Transition Matrix for $1999-2005$ for individuals who made more than $\$ 50,000$} \\
\hline & 2007 & Private E & Private D & Public & None \\
\hline \multirow[t]{4}{*}{2005} & Private E & 0.900 & 0.027 & 0.006 & 0.066 \\
\hline & Private D & 0.170 & 0.708 & 0.018 & 0.104 \\
\hline & Public & 0.119 & 0.000 & 0.763 & 0.118 \\
\hline & None & 0.600 & 0.026 & 0.087 & 0.286 \\
\hline
\end{tabular}

Conditional Probability Transition Matrix for 2005-2007 assuming high tax environment for individuals who made more than $\$ 50,000$

\begin{tabular}{cccccc}
\hline 2007 & Private E & Private D & Public & None \\
\hline 2005 & Private E & 0.858 & 0.016 & 0.003 & 0.123 \\
& Private D & 0.119 & 0.629 & 0.009 & 0.241 \\
& Public & 0.080 & 0.000 & 0.691 & 0.229 \\
None & 0.515 & 0.015 & 0.056 & 0.414 \\
\hline
\end{tabular}

Conditional Probability Transition Matrix for 2005-2007 assuming low tax environment for individuals who made more than $\$ 50,000$

Comparing the changes in the transitional probabilities for the high and low tax environments with the average transition matrix produces different results than what was observed with the other income group. For a high tax burden the transitional probabilities for both types of private insurance increase slightly, while the probability of transitioning into a no insurance category decreases. Comparing the low tax environment to the average, the probability of transitioning into the no insurance category increases while the probability of transitioning into either type of private insurance decreases. It appears that the probability of transitioning into private or public insurance is greater in a high tax environment 
than a low tax environment. This result is somewhat surprising. In high tax environments it appears that high-income individuals prefer private health insurance. This could be a result of the U.S. tax policy regarding health insurance. As noted above, previous research has concluded that higher income individuals are more likely to have health insurance through their employer. Thus, we believe that in a high tax environment high-income individuals buy more health insurance than they otherwise would have in order to lower their tax burden through tax benefits associated with private insurance. This conclusion is strengthened by noting that in low tax environments the probability that higher-income individuals purchase private health is lower even though more wealth is available. It should also be noted that the magnitude of the change in the transition probabilities for the low tax environment was greatest for high-income individuals.

\section{Conclusion}

This research has provided a novel way to study the distribution of coverage through transition matrices and estimate the movement of individuals among health insurance types conditional on specific tax environments. We have provided further evidence of the regressive nature of the effects of U.S. tax policy on the distribution of coverage.

There are several conclusions from this study that could have implications to health care policy makers. First, if the goal is to decrease those who are uninsured or covered by public insurance then reducing the tax burden does not appear to be an effective tool. In high tax environments all income levels seem to reduce the number of those uninsured but the number covered by public programs increases. Thus, any change in tax policy should ensure that the revenue received from the increase in the tax burden should be large enough to offset the increased funding required for the broader public coverage. Second, compared to higher income groups, lower income individuals have the lowest probability of being able to keep insurance through their employer regardless of the tax environment. Tax preference for employment based insurance does not appear to benefit low income individuals. Thus, we agree with Selden and Bernard (2004) that individuals with higher income benefit more from tax preferences for employment based insurance than do low income individuals. It should be noted that the elimination of the tax preference for employment based insurance could exacerbate adverse selection. However, the probabilities that individuals transition out of an insurance state into the None insurance state decreased in both income brackets in a high tax environment. Thus, our analysis leads us to the conclusion that if adverse selection is exacerbated it will not leave more individuals without insurance.

One last item that needs to be concluded about this study is that future research is needed in this field. The authors do realize that the results are from 
one empirical data set and a more specific way to measure the average tax burden needs to be developed. The results presented in this study are not intended to give strict health care tax rules. The study is only intended to give insight into how the tax burdens affect the movement of individuals among different insurance categories.

\section{References}

Bloche, G. M. (2006). Perspective: Tax preferences for nonprofits: from per se exemption to pay-for-performance. Health Affairs web exclusives January, W304-W307.

Feldman, R. , Dowd, B. E. and Maciejewski, M. (2001). A demand-side view of risk adjustment. Inquiry 38, 208-289.

Finger, C. C. (1999). Conditional approaches for credit metrics portfolio distributions. CreditMetrics Monitor Second Quarter, 14-26.

Florence, C. and Thorpe, K. E. (2003). How does the employer contribution for the federal employees health benefits program influence plan selection? Health Affairs 22, 211-218.

Forest, L. R. , Belkin, B. Jr. and Suchower, S. J. (1998). A one-parameter representation of credit risk and transition matrices. Credit Metrics Monitor Third Quarter, 46-56.

Gordy, M. B. (2002). A risk-factor model foundation for ratings-based bank capital rules. Journal of Financial Intermediation 12, 199-233.

Ketsche, P. G. (2004). An analysis of the effect of tax policy on health insurance purchases by risk group. Journal of Risk and Insurance 71, 91-113.

Selden, T. M. (1999). Premium subsidies for health insurance: excessive coverage vs. adverse selection. Journal of Health Economics 18, 709-725.

Selden, T. M. and Bernard, D. M. (2004). Tax incidence and net benefits in the market for employment-related health insurance: sensitivity of estimates to the incidence of employer costs. International Journal of Health Care Finance and Economics 4, 167-192.

Selden, T. M. and Gray, B. M. (2006). Tax subsidies for employment-related health insurance: Estimates for 2006. Health Affairs 25, 1568-1579.

Received February 5, 2009; accepted June 14, 2009. 
Eric D. Olson

Department of Economics and Finance

University of Alabama at Tuscaloosa

Alabama, USA

olson005@bama.ua.edu

Billie S. Anderson

SAS Institute

100 SAS Campus Dr.

Cary, NC 27513, USA

Billie.Anderson@sas.com

J. Michael Hardin

College of Commerce and Business Administration

Uiversity of Alabama

Tuscaloosa, AL 35487, USA

mhardin@cba.ua.edu 